\title{
Allgemeine Volkswirtschaftspolitik
}

\author{
von \\ Dr. Hans Ohm \\ o. Prof, an der Universität Würzburg \\ I \\ Systematisch-theoretische Grundlagen
}

3., verb. und ergänzte Auflage

Mit 7 Abbildungen

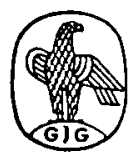

Sammlung Göschen Band 1195

Walter de Gruyter \& Co. · Berlin 1969

vormals G. J. Göschen'sche Verlagshandlung - J. Guttentag, Verlagsbuchhandlung - Georg Reimer - Karl J. Trübner - Veit \& Comp. 
Die Gesamtdarstellung umfaßt folgende Bände:

Band I: Systematisch-theoretische Grundlagen

Band II: Der volkswirtschaftliche Gesamtorganismus als Objekt der Wirtschaftspolitik

(C)

Copyright 1969 by Walter de Gruyter \& Co., vormals G. J. Göschen'sche Verlagshandlung - J. Guttentag, Verlagsbuchhandlung - Georg Reimer Karl J. Trübner - Veit \& Comp., Berlin 30. - Alle Rechte, einschI. der Rechte der Herstellung von Photokopien und Mikrofilmen vom Verlag vorbehalten. - Archiv-Nr. 7539 690. - Satz und Drudk:

Paul Funk, Berlin 30. - Printed in Germany. 